\title{
CONTACT PHONOLOGY : FONOLOGI KATA SERAPAN DALAM BAHASA JEPANG
}

\author{
I Gede Oeinada \\ Program Studi Sastra Jepang \\ Fakultas Ilmu Budaya Universitas Udayana
}

\begin{abstract}
:
This paper focuses its discussion about loanword phonology in Japanese language. Loanword phonology is one of five contact phonology situations that was described by Smith (2007). The four other situations are areal influence, dialect mixing, language mixing, and simplification. Japanese language has been borrowing many words from foreign languages. One of those foreign languages is English. As we all know that both languages, Japanese and English, have different phonological system. Therefore, borrowed words of English language has been adapted to fit the phonological patterns of Japanese language. This adaptation could solve the loanword phonology problem. And because up until now the number of loanword in Japanese language is till limited so the phonological system of Japanese language is remain unaffected. In other words, the loadwords' phonology does not cause lasting changes in the phonological system of Japanese language.
\end{abstract}

Key words: Contact Phonology, Japanese Loanword Phonology, Orthographic Interference

\section{PENDAHULUAN}

Contact Phonology adalah subdisiplin Fonologi yang mengkaji fenomena fonologi yang terjadi akibat kontak antar bahasa ataupun dialek. Contact Phonology merupakan aspek Phonology in Context yang berkaitan dengan bilingualisme dan multilingualisme serta sejarah dan perkembangan suatu bahasa ataupun dialek. Kajian contact phonology ini dapat memperdalam pemahaman kita akan bilingualisme dan multilingualisme serta sejarah dan perkembangan suatu bahasa ataupun dialek dan juga menyediakan landasan teoretis untuk pengkajian perubahan bahasa (language change) dan karakteristik sistem fonologi (the nature of phonological systems).

Terdapat dua aspek penting berkaitan dengan contact phonology. Pertama, terkait dengan karakteristik pasti kontak linguistik (the precise nature of the linguistic contact). Kedua, terkait dengan tipe fenomena fonologiyang dapat dialihkan (the type of phonological phenomenon that can be transferred). Contact Phonology merupakan bagian dari kontak linguistik (linguistic contact) yang dapat dibagi menjadi lima tipe situasi, yaitu:

i. Fonologi kata serapan (loanword phonology)

ii. Pengaruh area (areal influence)

iii. Percampuran dialek (dialect mixing)

iv. Percampuran bahasa (language mixing)

v. Penyerderhanaan (simplification)

Pada tulisan ini, pembahasan dibatasi hanya pada tipe situasi pertama, yakni fonologi kata serapan dengan menggunakan data berupa katakata asing yang telah diserap ke dalam bahasa Jepang (loanwords).

\section{TINJAUAN PUSTAKA}

Pertama-tama, akan dijelaskan mengenai kelima tipe situasi contact phonology menurut Smith (2007).

\subsection{Lima Situasi Contact Phonology}

i. Fonologi kata serapan (loanword phonology) Tipe situasi ini terkait dengan strategi-strategi 
ketika pembicara menggunakan item-item leksikal suatu bahasa pada bahasa lain dalam skala besar dan waktu yang singkat. Biasanya hal ini terjadi pada situasi dominasi budaya, yaitu orang-orang dari budaya yang didominasi menggunakan item-item leksikal bahasa dari budaya yang mendominasi. Kata-kata serapan akan melibatkan fonologi kata serapan (loanword phonology) apabila kedua bahasa tersebut memiliki sistem bunyi (fonologi) yang berbeda. Apabila jumlah kata-kata serapan banyak, dapat menimbulkan perubahan yang tetap pada sistem bunyi bahasa yang meminjam/menyerap item-item leksikal tersebut. Namun, apabila jumlah kata-kata serapan sedikit, tidak dapat menimbulkan perubahan yang tetap pada sistem bunyi bahasa yang meminjam/ menyerap item-item leksikal tersebut tetapi fonologi item-item leksikal kata-kata serapan tersebutlah yang diadaptasi agar menyesuaikan pola bunyi bahasa yang meminjam/menyerap item-item leksikal tersebut. Contoh dalam bahasa Jepang adalah ketika menyerap kata-kata dengan fonem /ə/ dalam bahasa Indonesia maka orangorang Jepang akan menyuarakan bunyi [u] dalam bahasa Jepang. Misalnya, kata "Bedugul" [bə dugul] akan disuarakan menjadi [buduguru] oleh orang-orang Jepang. Demikian pula dengan fonem /l/ yang tidak dibedakan dengan /r/ dalam bahasa Jepang sehingga kata "Bali" [bali] akan disuarakan menjadi [bari] oleh orang-orang Jepang.

\section{ii. Pengaruh area (areal influence)}

Tipe situasi ini terkait dengan penggunaan beberapa bahasa secara stabil dan intim dalam suatu wilayah geografis terbatas selama jangka waktu yang lama. Akibatnya, para penutur di wilayah tersebut memiliki kemampuan bilingualisme sehingga lama kelamaan akan terjadi konvergensi sistem bunyi (phonological systems) bahasa-bahasa yang digunakan oleh para penutur di wilayah tersebut. Sebagaimana yang kita ketahui bahwa dialek-dialek yang saling berdekatan secara geografis akan memberikan pengaruh satu sama lain (bidialectalism). Demikian pula halnya dengan bahasa-bahasa yang saling berdekatan secara geografis akan memberikan pengaruh satu sama lain (bilingualism).

\section{iii. Percampuran dialek (dialect mixing)}

Tipe situasi ini terkait dengan percampuran berbagai tipe dialek. Hal ini dapat disebabkan oleh:

a. Percampuran dialek lokal yang saling bertetangga

b. Perpindahan (migrasi) penduduk ke suatu daerah yang berasal dari satu daerah yang sama

c. Penciptaan variasi bahasa baru yang tidak dapat diidentifikasi ke dialek-dialek utama di daerah tersebut (koiné formation)

d. Pelemahan dialek lokal sebagai akibat komunikasi modern (regional koiné/ regiolect)

e. Pengaruh bahasa standar terhadap dialekdialek lokal

\section{iv. Percampuran bahasa (language mixing)}

Tipe situasi ini terkait dengan munculnya bahasa-bahasa baru sebagai akibat bilingualisme yang menyebabkan bercampurnya dua bahasa yang berbeda. Kedua bahasa yang berbeda tersebut umumnya memiliki sistem bunyi yang berbeda. Bahasa yang baru itu pun tidak dianggap sebagai bahasa yang layak untuk kajian ilmiah. Situasi yang mungkin terjadi akibat percampuran bahasa ini adalah:
a. Dua sistem bunyi
b. Satu sistem bunyi
c. Split Prosody (dua sumber kosakata)

\section{v. Penyerderhanaan (simplification)}

Tipe situasi ini terkait dengan pidginization dan/atau creolization yang terjadi pada tataran fonologi. Pidgin merupakan bahasa yang tercipta karena faktor komunikasi antarpenutur bahasa yang bebeda yang menciptakan suatu sistem bahasa tertentu dengan memanfaatkan unsur bahasa yang ada dan digunakan oleh kedua masyakata tutur tersebut. Sedangkan kreole adalah kelanjutan pidgin yang mempunyai penutur asli sebagai bahasa baru yang resmi serta mengalami perubahan bentuk dan fungsi (Setyawan, 2016). 


\subsection{Penulisan Kata-Kata Serapan dalam}

\section{Bahasa Jepang}

Bahasa Jepang merupakan bahasa bersuku kata terbuka (Kawarazaki, 2007). Bahasa Jepang juga termasuk bahasa fonemik. Dalam bahasa Jepang, untuk mengidentifikasi kata-kata serapan adalah sangat mudah. Hal ini disebabkan karena orang Jepang mempergunakan 4 set huruf dalam kehidupan mereka sehari-hari. Keempat set huruf tersebut adalah Kanji, Hiragana, Katakana, dan Romaji. dalam aturan penggunaan set huruf tersebut, kata-kata serapan selalu akan ditulis menggunakan set huruf Katakana. Hiragana digunakan pada umumnya untuk menuliskan kata tugas(function words). Sedangkan, Kanjidigunakan untuk menuliskan kata bermakna (content words). Pada mulanya, Kanji berasal dari negara Tiongkok. Namun, dalam perkembangannya, orang-orang Jepang pun menciptakan Kanji-Kanji mereka sendiri. Jumlah Kanji yang diharuskan dikuasai oleh pemerintah Jepang yakni sejumlah 2.136 huruf yang disebut dengan 常用漢字 Jouyou Kanji (Sakade dan Ikeda, 2013). Baik Hiragana dan Katakana sebenarnya berasal dari Kanji yang dimodifikasi. Sedangkan, Romaji adalah huruf Latin berupa alfabet a $\sim$.

Berikut adalah 48 huruf Katakana dasar beserta asal huruf Kanji mereka (Kida, 2011:117).

\begin{tabular}{|c|c|c|c|c|c|c|c|c|c|c|}
\hline V & 7 & $>$ & + & 7 & 八 & + & 8 & サ & 力 & $r$ \\
\hline 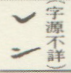 & $\begin{array}{l}\text { 和 } \\
\text { י }\end{array}$ & $\begin{array}{l}\text { 良 } \\
\text { 方 }\end{array}$ & 也 & $\div$ & $\therefore$ & 奈 & 多 & $\begin{array}{l}\text { 散 } \\
\text { \# }\end{array}$ & 加 & $\begin{array}{l}\text { 阿 } \\
P\end{array}$ \\
\hline & + & 1) & 1 & $\equiv$ & $t$ & $=$ & F & $=$ & + & 1 \\
\hline & $\begin{array}{l}\text { 并 } \\
\text { 并 }\end{array}$ & $\begin{array}{l}\text { 利 } \\
\text { y }\end{array}$ & & $\bar{\Sigma}$ & $\begin{array}{l}\text { 比 } \\
\text { E }\end{array}$ & $=$ & $\begin{array}{l}千 \\
4\end{array}$ & $\begin{array}{l}z \\
i\end{array}$ & \begin{tabular}{l} 
幾 \\
\multirow{1}{*}{}
\end{tabular} & $\begin{array}{l}\text { 伊 } \\
3\end{array}$ \\
\hline & 3 & ル & 7 & $\angle$ & 7 & 7 & $y$ & $x$ & 7 & ウ \\
\hline & & 流 & $\begin{array}{l}\text { 由 } \\
2\end{array}$ & $\begin{array}{l}\text { 年 } \\
2\end{array}$ & $\begin{array}{l}\text { 不 } \\
7\end{array}$ & $\begin{array}{l}\text { 奴 } \\
2\end{array}$ & 州 & $\begin{array}{l}\text { 須 } \\
\text { 万 }\end{array}$ & $\begin{array}{l}2 \\
7\end{array}$ & 宇 \\
\hline & I & $L$ & $x$ & $x$ & 1 & $\star$ & $\bar{T}$ & $t$ & 4 & $I$ \\
\hline & 恵 & $\begin{array}{l}\text { 礼 } \\
\text { L }\end{array}$ & 1 & $\begin{array}{l}\text { 女 } \\
x\end{array}$ & 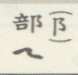 & $\begin{array}{l}\text { 袮 } \\
\text { 示 }\end{array}$ & $\begin{array}{l}\text { 天 } \\
\bar{T}\end{array}$ & $\begin{array}{l}\text { 世 } \\
\text { せ }\end{array}$ & $\begin{array}{l}\text { 介 } \\
\text { ケ }\end{array}$ & $\begin{array}{l}\text { 江 } \\
\text { I }\end{array}$ \\
\hline & 7 & $\square$ & $\exists$ & $E$ & ホ & 1 & 1 & $y$ & ב & t \\
\hline & $\begin{array}{l}\text { 乎 } \\
\text { y }\end{array}$ & $\begin{array}{l}\text { 몸 } \\
a\end{array}$ & $\begin{array}{l}\text { 与 } \\
7\end{array}$ & $\begin{array}{l}\text { 毛 } \\
\text { E }\end{array}$ & $\begin{array}{l}\text { 保 } \\
\neq\end{array}$ & 3 & 止 & $\begin{array}{l}\text { 曾 } \\
\text { 一 }\end{array}$ & $\begin{array}{l}己 \\
2\end{array}$ & $\begin{array}{l}\text { 於 } \\
\text { 才 }\end{array}$ \\
\hline
\end{tabular}

Gambar 1. Set Huruf Katakana

\section{METODOLOGI}

Sumber data tulisan ini mempergunakan artikel dalam majalah Hiragana Times edisi bulan Agustus 2017 (ISSN 1348-7906, no.370, halaman 34-35). artikel tersebut berjudul 日本の古い古典文学は
素晴らしいエンターテイメント Nihon no Koten Bungaku wa Subarashii Entaateimento 'Sastra Jepang Klasik adalah Hiburan yang Sangat Bagus'. Kata-kata serapan dalam bahasa Jepang akan dicari, diamati dan didokumentasikan. Setelah itu, data berupa kata-kata serapan yang telah didokumentasikan tersebut dibandingkan dengan kata aslinya untuk melihat penerapan kaidah fonologi terhadap kata-kata serapan tersebut. Metode penelitian dalam tulisan ini menggunakan metode penelitian kualitatif-deskripsi.

Dalam sumber data, ditemukan kata-kata serapan sebagai berikut:

\begin{tabular}{|c|c|c|c|c|}
\hline No & Kata Serapan & Kata Asli & No Kata Serapan & Kata Asli \\
\hline 1 & $\begin{array}{l}\text { エン㚶チ怆イ } \\
\text { [entatte]men- }\end{array}$ & $\begin{array}{c}\text { entertainment } \\
\text { 'hiburan' }\end{array}$ & $t_{2} \begin{array}{c}\text { ヴェネツィア } \\
\text { [venetsia] }\end{array}$ & $\begin{array}{c}\text { Venice } \\
\text { '(kots)aVen- }\end{array}$ \\
\hline 3 & $\begin{array}{l}\text { ハンサム } \\
\text { [hansamu] }\end{array}$ & $\begin{array}{l}\text { handsome } \\
\text { 'tampan' }\end{array}$ & $\begin{array}{c}\text { イザベラ・デ } \\
\text { イオニジ } \\
4 \\
\\
\\
\text { dionishiora }\end{array}$ & $\begin{array}{l}\text { Isabella Di- } \\
\text { onisio '(nama } \\
\text { orang)' }\end{array}$ \\
\hline 5 & $\begin{array}{c}\text { アニメ } \\
\text { [anime] }\end{array}$ & $\begin{array}{l}\text { animation } \\
\text { 'kartun' }\end{array}$ & $\begin{array}{c}\text { ブーム } \\
\text { [bu:mu] }\end{array}$ & $\begin{array}{c}\text { boom } \\
\text { 'ledakan' }\end{array}$ \\
\hline 7 & $\begin{array}{l}\text { ファン } \\
\text { [fan] }\end{array}$ & $\begin{array}{c}\text { fan } \\
\text { 'penggemar' }\end{array}$ & $\begin{array}{l}\text { イタリア } \\
\text { [itaria] }\end{array}$ & $\begin{array}{c}\text { Italy } \\
\text { '(negara) Itali' }\end{array}$ \\
\hline 9 & $\begin{array}{c}\text { ギャグ } \\
\text { [gyagu] }\end{array}$ & $\begin{array}{c}g a g \\
\text { 'lelucon' }\end{array}$ & $\begin{array}{l}\text { スラング } \\
\text { [surangu] }\end{array}$ & $\begin{array}{c}\text { slang 'ucapan } \\
\text { populer' }\end{array}$ \\
\hline 11 & $\begin{array}{c}\text { クラスメート } \\
\text { [kurasume:to] }\end{array}$ & $\begin{array}{c}\text { classmate } \\
\text { ‘temams'seke- }\end{array}$ & $\begin{array}{l}\text { ギリシャ } \\
\text { [girisha] }\end{array}$ & $\begin{array}{l}\text { Greece“ } \\
\text { (intgani) }\end{array}$ \\
\hline 13 & $\begin{array}{l}\text { カフェ } \\
{[\mathrm{kafe}]}\end{array}$ & $\begin{array}{c}\text { cafe } \\
\text { 'warung kopi' }\end{array}$ & $\begin{array}{ll} & \text { アルバイト } \\
14 & \text { [arubaito] }\end{array}$ & $\begin{array}{c}\text { arbeiten } \\
\text { (bhs. Jerman) } \\
\text { 'bekerja' }\end{array}$ \\
\hline 15 & $\begin{array}{c}\text { ラテ } \\
\text { [rate] }\end{array}$ & $\begin{array}{c}\text { latte } \\
\text { (bhs. Italia) } \\
\text { 'susu' }\end{array}$ & $16 \begin{array}{c}\text { カフェラテ } \\
\text { [kaferate] }\end{array}$ & $\begin{array}{c}\text { Caffè latte } \\
\text { (bhs. Italia) } \\
\text { 'kopi susu' }\end{array}$ \\
\hline 17 & $\begin{array}{c}\text { ストレス } \\
\text { [sutoresu] }\end{array}$ & $\begin{array}{l}\text { stress } \\
\text { 'stres' }\end{array}$ & $\begin{array}{c}\text { ロッカ厶加 } \\
\text { [rok:a:ru:mu] }\end{array}$ & $\begin{array}{l}\text { locker room, } \\
\text { 'kamar ganti' }\end{array}$ \\
\hline 19 & $\begin{array}{c}\text { コーテイィネ } \\
\text { [ko:dine:to] }\end{array}$ & $\begin{array}{l}\text { coordinate } \\
\text { 'mengoordi- } \\
\text { nasikan' }\end{array}$ & & \\
\hline
\end{tabular}

\section{HASIL dan PEMBAHASAN}

Pada tabel kata-kata serapan dalam artikel yang dijadikan sumber data, ditemukan 19 kata serapan bahasa Jepang. Kata-kata serapan tersebut tidak seluruhnya berasal dari bahasa Inggris. Terdapat satu kata serapan yang berasal dari bahasa Jerman, yaitu アルバイト [arubaito] 'bekerja paruh waktu' serta terdapat pula dua kata serapan yang berasal dari bahasa Italia, yaitu ラテ [rate] 'kopi susu' dan カフェラテ [kaferate] 'kopi susu'.

Apabila dicermati data kata-kata serapan bahasa Jepang yang ditemukan, terdapat beberapa kaidah 
fonologi yang diterapkan pada kata-kata serapan tersebut. kaidah fonologi kata serapan tersebut dapat dikelompokkan sebagai berikut.

\subsection{Penyesuaian Bunyi}

a) Pemilihan Bunyi Konsonan Terdekat

Data (11), (12), dan (13) menunjukkan pemilihan bunyi konsonan terdekat. Adaptasi terhadap konsonan kata-kata serapan dalam bahasa Jepang didasari pada kemiripan bunyi terdekat. Misalnya konsonan $c$ dari kata asli bahasa Inggris bukanlah menjadi patokan adaptasi fonologi ke dalam bahasa Jepang. Melainkan, bagaimana konsonan c tersebut disuarakan dalam kata itulah yang menjadi pedoman adaptasi fonologi ke dalam bahasa Jepang.
(11) Classmate [kláss màyt] $\rightarrow$ [kurasume:to]
(12) Greece [gri:ss] $\rightarrow$ [girisha]

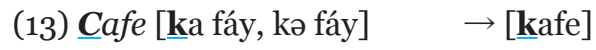

Dapat dilihat pada data (11), (12), dan (13) bahwa meskipun sama-sama mengandung konsonan $c$ pada kata aslinya, tetapi mengalami proses adaptasi menjadi konsonan yang berbedabeda dalam bahasa Jepang tergantung pada bunyi konsonan terdekat. Dengan kata lain, kaidah adaptasi fonologi bahasa Jepang terhadap katakata serapan adalah bergantung pada bunyi/ penyuaraan kata asli kata-kata serapan tersebut yang dicarikan bunyi terdekatnya dalam bahasa Jepang.

b) Vokal Panjang Terhadap \{-ər\} dan \{-o:\}

Data (1) dan (18) menunjukkan bahwa terhadap $\{-\partial r\}$, terjadi penyesuaian yakni dengan membuat vokal panjang [-a:].

(1) Entertainment [èntor táynmənt] $\rightarrow$ [enta:teimento]

(18) Locker room [lpk.ọ.ru:m] $\rightarrow$ [rok:a:ru:mu]

Sedangkan, untuk bunyi vokal panjang \{-o:\}, terjadi penyesuaian sesuai dengan bunyi vokal panjang tersebut dalam bahasa aslinya sehingga dapat bervariasi menjadi [u:] ataupun [o:] seperti terlihat pada data (6), (18), dan (9) berikut:
(6) boom [bu:m]
$\rightarrow$ [bu:mu]
(18) Locker room [lok.ə.rüm] $\rightarrow$ [rok:a:ru:mu]
(19) coordinate [kov' orr di.nert] $\rightarrow$ [ko:dine:to]

\subsection{Penambahan Vokal}

Data (1), (9), (10), (14), (17) adalah beberapa contoh penambahan vokal di akhir konsonan sehingga menjadikan konsonan tersebut sebuah suku kata terbuka.
(1) Entertainment [èntər táynmənt] $\rightarrow$ [enta:teimento]
(9) Gag [gæg]
$\rightarrow$ [gyagu]
(10) Slang [slæu]
$\rightarrow$ [surangu]
(14) arbeiten [arbeitən]
$\rightarrow$ [arubaito]
(17) Stress [stres]
$\rightarrow$ [sutoresu]

Sesuai dengan sifat bahasa Jepang yakni merupakan bahasa bersuku kata terbuka dan termasuk bahasa fonemik maka kaidah adaptasi fonologi kata-kata serapan pun menyesuaikan dengan bunyi terdekat kata-kata serapan tersebut yang disesuaikan dengan fonologi bahasa Jepang. Penambahan vokal untuk menjadikan suatu konsonan menjadi suku kata terbuka, tergantung pada konsonan tersebut. pada data terlihat bahwa konsonan $[t]$ akan mendapat tambahan vokal [o], sedangkan konsonan lainnya akan mendapatkan tambahan vokal [u]. Bahasa Jepang tidak membedakan fonem /l/ dan /r/ sebagaimana yang dapat dilihat pada penyuaraan [slang] menjadi [suranggu] atau dengan kata lain, keduanya merupakan alofon.

\section{SIMPULAN}

Kontak bahasa merupakan kekuatan yang menyebabkan perubahan pada banyak aspek fonologi bahasa-bahasa di dunia. Hal ini dapat dilihat pada set Katakana bahasa Jepang yang memiliki variasi bunyi lebih banyak untuk melambangkan pengucapan kata-kata serapan bahasa asing daripada Hiragana. Hasil pengamatan pada data menunjukkan bahwa sebagian besar kata-kata serapan ke dalam bahasa Jepang berasal dari bahasa Inggris. Untuk mengadaptasi perbedaan fonologi sistem bahasa asal kata-kata serapan tersebut, sistem fonologi bahasa Jepang melakukan beberapa penyesuaian bunyi terhadap 
kata-kata serapan tersebut antara lain dengan cara: (1)penyesuaian bunyi, yang dapat dirinci lagi menjadi: (a) pemilihan bunyi konsonan terdekat; (b) vokal panjang terhadap $\{-\partial r\}$ dan $\{-0:\} ;$ (2) penambahan vokal.

Penambahan data untuk melihat lebih jauh kaidah-kaidah penyesuian sitem fonologis katakata serapan tentunya akan sangat membantu pemahaman lebih lanjut terhadap fenomena fonologi kata serapan bahasa Jepang ini.

\section{REFERENSI}

Echols, John M. Dan Hassan Shadily. 2007. Kamus Inggris Indonesia. Jakarta: PT. Gramedia Pustaka Utama.

Kawarazaki, Miko. 2007. Nihongo: Kana - An Introduction to the Japanese Syllabary. Tokyo:
Bonjinsha.

Kida, Mari, dkk. 2011. Moji-Goi wo Oshieru. Tokyo: The Japan Foundation.

Matsuura, Kenji. 2005. Kamus Jepang-Indonesia. Jakarta: Gramedia Pustaka Utama.

Sakade, Florence dan Janet Ikeda. 2013. A Guide to Reading and Writing Japanese. Hongkong: Tuttle Publishing.

Setyawan, Aan. 2016. "Pengertian dan Perbedaan Antara Creole dan Pidgin”. https://m.belajarbahasa. id/artikel/dokumen/95-pengertian-dan-perbedaanantara-creole-dan-pidgin-2016-07-22-04-51 diakses tanggal 10 Oktober 2017 pukul 20.45.

Smith, Norval. 2007. Contact Phonology dalam Pennington, Martha C. (Eds). Phonology in Context (hal.76-107). Hampshire: Palgrave Macmillan. 